\title{
Influence of soil-atmosphere interactions and unsaturated soil properties on slope stability
}

\author{
Murilo Pereira da Silva Conceição ${ }^{1}$, Camilla Maria Torres Pinto ${ }^{1}$, Fernando Antonio Leite Vieira Lima ${ }^{1,2}$, and Sandro \\ Lemos Machado ${ }^{1, *}$ \\ ${ }^{1}$ Federal University of Bahia, Department of Materials Science and Technology - Prof. Aristides Novis 2, Federação, Salvador, \\ Bahia,Brazil \\ ${ }^{2}$ Lund University, Lunds Tekniska Högskola, Solid Mechanics Division - Ole Römersväg 1, Lund, Skåne, Sweden
}

\begin{abstract}
Results of coupled slope stability analysis performed on two urban slopes in Salvador-BA, considering suction variations due to soil-atmosphere interactions over the years of 2016 and 2018 are presented. Boundary conditions, unsaturated soil shear strength and hydraulic parameters were determined by surveying the local topography, analysing climatic and hydrological data, and gathering undisturbed soil samples from the slopes. Soil characterization, saturated and suction controlled triaxial tests and permeability, evaporation and soil water retention curve tests were performed. The simulation of the slope stability over time was performed using SEEP/W and SLOPE/W. A "soil-climate interaction function" and a modifier function were used as two distinct approaches to model the interactions between soil and the environment. The Vanapalli et al. (1996) [1] and Fredlund et al. (1978) [2] models were used to fit the cohesion versus suction curves. The most severe stability conditions were obtained in modelling considering the modifier function for soil-atmosphere interaction and Vanapalli et al. (1996) [1] model for slope 2 and the model of Fredlund et al. (1978) [2] for slope 1.
\end{abstract}

\section{Introduction}

Slope instability problems are intrinsic to Civil and Geotechnical Engineering's daily routine in dealing with landfills, dams, and other earthworks. Most of the time, stability conditions are aggravated by climatic and hydrological issues (VILAR, 2007) [3]. A more accurate assessment of these interactions is necessary to address the real possibility of failure. Although the saturated condition typically yields the worst scenario of shear strength and deformability, in many situations, the slope may never reach a fully saturated state, even under severe precipitation regimes (SOUSA, 2006) [4]. Thus, it is necessary to know the variations in soil properties due to seasonal drying and wetting processes. Furthermore, the lack of analysis of the soil-atmosphere interaction may lead to a misinterpretation of the problem and retaining structures can be demanded.

In this work, two urban slopes located at Salvador-BA were studied. Geotechnical analyses were carried out to integrate soil strength parameters, hydrological, topographic, and climatic aspects. Two different soilclimate interaction approaches were considered in the performed analysis. Weathering data was integrated into the SLOPE/W software, and slope stability analysis over time was performed considering two distinct shear strength models: Fredlund et al. (1978) [2] and Vanapalli et al. (1996) [1].

\subsection{The mechanical behaviour of unsaturated soils}

According to the definitions of Classical Soil Mechanics, the shear strength of saturated soils is directly linked to the effects of friction and soil cohesion and the interstitial water pressure, forming the well stablished Principle of Effective Stresses (TERZAGUI, 1925,1936) [6] [7]. The dynamics of fluids across saturated soils, in its turn, will depend on the water energy gradients, the hydrodynamic properties of the fluid, and the size, shape, and distribution of soil particles (DARCY, 1856 [8]; NUTTING, 1930 [9]). Several studies (FREDLUND ET AL., 1978 [1]; ESCARIO AND SÁEZ, 1986 [10]; ESCARIO AND JUCÁ, 1989 [11]) also address the role of the negative water pressures (or suction) in the mechanical behaviour of unsaturated sandy and clayey soils for different moistures and, consequently, different levels of matric suction. Moisture and suction, which are related by the soil water retention curve, SWRC, affect the available transverse area for water flow and the water energy and, therefore, the hydraulic potential and soil conductivity.

\footnotetext{
* Corresponding author: smachado@ufba.br
} 
1.1.1 Suction, Soil Water Retention Curve, Hydraulic Conductivity Curve and Soil-Climate Interaction

Soil matric suction can be defined as the resulting soil/water attractive forces due to the adsorption and capillarity phenomena. The measurement of soil suction in engineering practice is essential since this parameter has a decisive role in the mechanical and hydraulic behaviour of unsaturated soils.

Suction is a function of the soil structure (influenced by mineralogy and density) and water content. The relationship between soil suction (matric suction or total suction) and water content is called the soil water retention curve. The soil air entry value is the matric suction from which air begins to enter the largest voids of the soil (FREDLUND and XING, 1994 [12]). Residual moisture content is the moisture content from which a considerable variation of suction is required to remove additional water from the soil.

Several models have been used to describe the SWRC, among which we have the van Genuchten (1980) [13] and Fredlund and Xing (1994) [12] propositions. Although the model proposed by Fredlund and Xing (1994) [12] embrace the soil/water relationships until the complete drying of the soil, for sake of simplicity, the van Genuchten (1980) [13] model was adopted in this study. Van Genuchten (1980) [13] presented a class of functions representing the SWRC, Equation 1, and hydraulic conductivity function $\mathrm{k}(\psi)$, Equation 2, which describes the relationship between suction and soil permeability.

$$
\begin{aligned}
& \theta=\theta_{r}+\left(\theta_{s}-\theta_{r}\right)\left[\frac{1}{1+(\alpha \psi)^{n}}\right]^{m} \\
& k(\psi)=k_{\text {sat }} \frac{\left\{1-(\alpha \psi)^{n-1}\left[1+(\alpha \psi)^{n}\right]^{-m}\right\}^{2}}{\left[1+(\alpha \psi)^{n}\right]^{m / 2}}
\end{aligned}
$$

where:

$\theta_{\mathrm{s}}$ and $\theta_{\mathrm{r}}$ are the saturated and residual volumetric moisture contents, respectively and $\alpha, \mathrm{m} \mathrm{n}$ are fitting parameters. $\alpha$ is approximately the inverse of the air entry value; $\mathrm{k}_{\text {sat }}$ is the saturated permeability and $\psi$ is the soil matric suction.

Analyses involving unsaturated soils require understanding the water balance on the soil surface, accounting for the influence of atmosphere and vegetation. The two main processes that govern water exchange between the soil surface and the atmosphere are infiltration and evapotranspiration (VIVACQUA, 2012) [14].

Potential evaporation is governed by atmospheric demand, which depends mainly on solar radiation, temperature, relative humidity, and wind speed. It imposes a maximum evaporative flow rate when the soil is saturated. Due to the soil suction (and the corresponding decrease in the interstitial water energy) and the reduced hydraulic conductivity, evaporation rates decrease as the soil became drier (SÃO MATEUS ET AL., 2011 [15]). Some authors have proposed formulations that relate potential evaporation to actual evaporation in order to better represent the water exchange between atmosphere and soil. Among these, the proposal by Wilson et al. (1997) [16], Equation 3, stands out:

$$
E_{a}=E_{p}\left[\frac{p_{v s}-p_{v a}}{p_{v s 0}-p_{v a}}\right]
$$

Where $E_{a}$ and $E_{p}$ are the actual and potential evaporation rates, respectively; $p_{v s}$ and $p_{v a}$ are the partial vapor pressures at the surface of the soil and in the air above the soil, respectively and $p_{v s 0}$ is the vapor pressure at the surface of the soil for saturated conditions.

\subsubsection{Unsaturated Soil Shear Strength}

The unsaturated soil shear strength is typically evaluated using equations such as those proposed by Bishop (1959) [17] and Fredlund et al. (1978) [2] (Equations 4 and 5, respectively).

$$
\begin{gathered}
\tau=c^{\prime}+\left(\sigma_{n}-u_{a}\right) \tan \phi^{\prime}+\chi\left(u_{a}-u_{w}\right) \tan \phi^{\prime} \\
\tau=c^{\prime}+\left(\sigma_{n}-u_{a}\right) \tan \phi^{\prime}+\left(u_{a}-u_{w}\right) \tan \phi^{b}
\end{gathered}
$$

Where $\left(\sigma_{n}-u_{a}\right)$ is the net normal stress on the failure plane; $\left(\mathrm{u}_{\mathrm{a}}-\mathrm{u}_{\mathrm{w}}\right)$ is the soil matric suction; $\mathrm{c}^{\prime}$ and $\phi^{\prime}$ are the effective soil cohesion and friction angle, respectively, and $\chi$ and $\phi^{\mathrm{b}}$ are parameters that reflect the influence of the suction on the soil shear strength.

Vanapalli et al. (1996) [1] extended the theory proposed by Fredlund et al.(1978) [2] considering that $\phi^{b}$ is not constant with suction (Equation 6). In this model, the nonlinearity of the soil shear strength with suction is addressed (there is a decrease in the $\phi^{\mathrm{b}}$ values as suction increases).

$\tau=c^{\prime}+\left(\sigma_{n}-u_{a}\right) \tan \phi^{\prime}+\left(u_{a}-u_{w}\right)\left[\left(\frac{\theta-\theta_{r}}{\theta_{s}-\theta_{r}}\right) \tan \phi^{\prime}\right]$

(6)

All the previous equations reduce to Terzaghi's effective stress equation when $\mathrm{Sr}=1\left(\right.$ or $\left.\theta=\theta_{\mathrm{s}}\right)$.

\section{Materials and Methods}

\subsection{Study Area, Soil Sampling, and Topography Survey}

Both the study areas are in the Pau da Lima, a district in Salvador-BA, Brazil. The soil surface presents steep slope cuts, and the subsurface conditions are characterized by residual soil profiles of Granulite/Gneiss. Both areas are densely populated, and the construction pattern is low, without the necessary geotechnical analyses (Figure 1). 


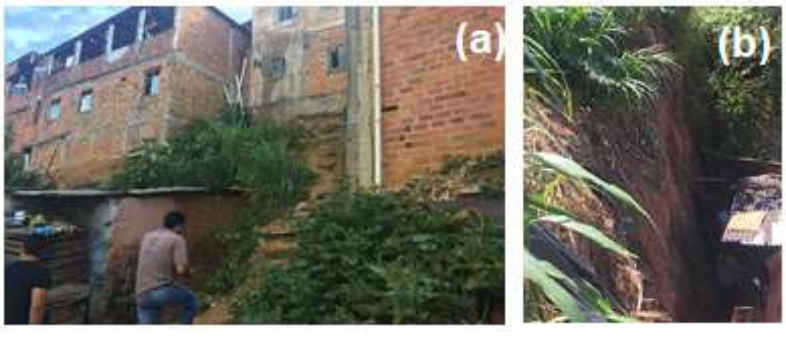

Fig. 1. Area Location: (a) Slope 1; (b) Slope 2.

Figure 2 shows the mapping of the study area 2, in which it is possible to observe the delimitation of the slope area, the surrounding urban occupations, and the most critical section analysed.

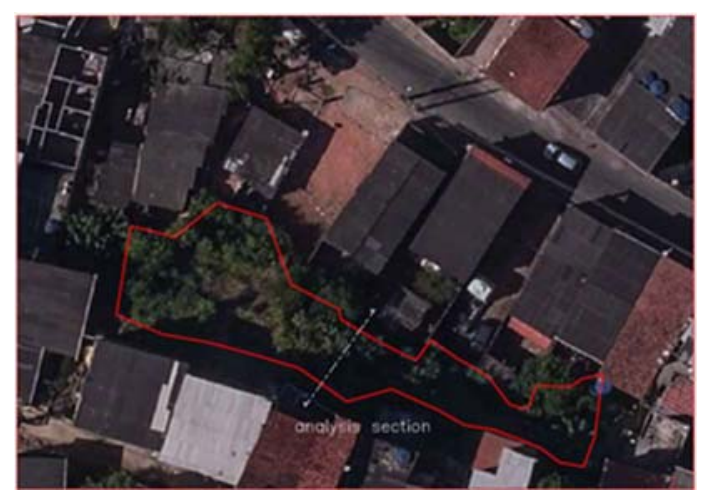

Fig. 2. Delimitation of slope 2 and most critical section analysed.

\subsection{Soil Characterization}

The soil characterization comprised the measurement of the specific gravity $\mathrm{G}_{\mathrm{s}}$; soil field moisture, $\theta$, porosity, $\mathrm{n}$; dry bulk density, $\rho_{\mathrm{d}}$ (Table 1); and SWRC determination (Table 2).

Table 1. Soil Properties.

\begin{tabular}{c|c|c|c|c}
\hline Soil & Gs & $\begin{array}{c}\mathbf{\rho d} \\
\left(\mathbf{g} / \mathbf{c m}^{3}\right)\end{array}$ & $\mathbf{n}$ & $\boldsymbol{\theta}(\mathbf{\%})$ \\
\hline Slope 1 & 2.92 & 1.24 & 0.57 & 28.1 \\
Slope 2 & 2.72 & 1.23 & 0.55 & 31.3 \\
\hline
\end{tabular}

Considering the clayey aspect of the subsurface soil, the WP4 - "Dewpoint Potential Meter" was used for SWRC determination (main drying branch). Then, the SWRC were fitted by the van Genuchten equation (1980) [13] (see Figure 3).

Table 2. SWRC fitted parameters

\begin{tabular}{c|c|c|c|c}
\hline Soil & $\boldsymbol{\alpha}$ & $\mathbf{m}$ & $\mathbf{n}$ & $\mathbf{R}^{\mathbf{2}}$ \\
\hline Slope 1 & 0.009 & 0.29 & 1.42 & 0.99 \\
Slope 2 & 0.004 & 0.51 & 2.01 & 0.93 \\
\hline
\end{tabular}

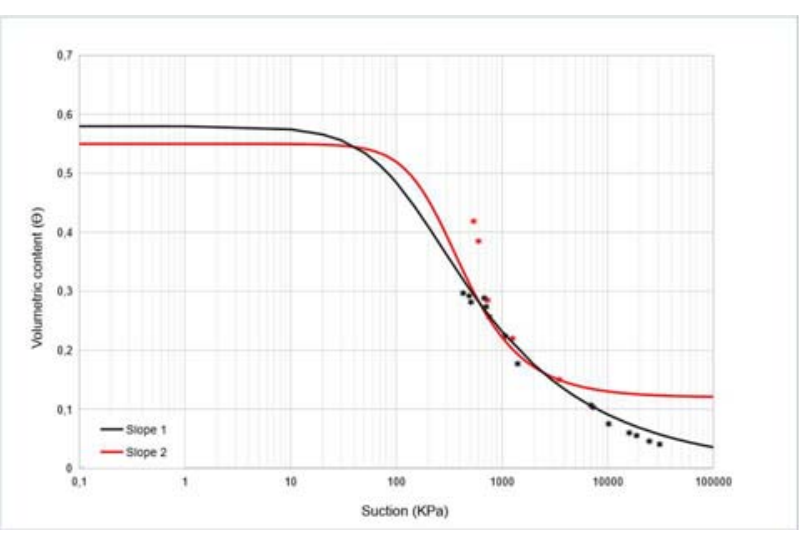

Fig. 3. Soil Water Retention Curves for slopes 1 and 2..

\subsection{Field Evaporation and Potential Evaporation}

Evaporation tests were carried out to determine the ratio between field and potential evaporation for different moisture/suction values. In such tests, the loss of water mass to the environment in a container with water was monitored over time and then compared to the loss of mass presented by an undisturbed sample, initially saturated under similar conditions. Figure 4 shows the soil and water samples exposed to the environment.

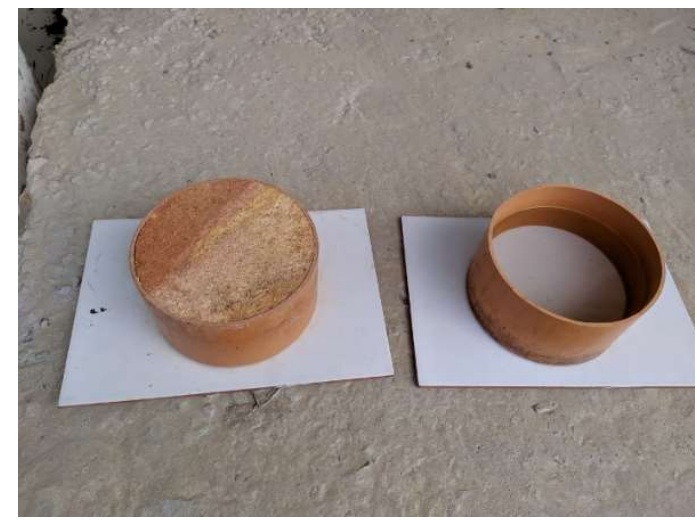

Fig. 4. Specimens exposed to atmospheric conditions in performed evaporation tests.

\subsection{Determination of Shear Strength}

Strength parameters were obtained by performing triaxial tests. The samples were divided into three groups of imposed suction: air-dried $(\sim 100.000 \mathrm{kPa})$, imposed suctions of $50 \mathrm{kPa}$ and $500 \mathrm{kPa}$, and saturated. Specimens from slope 1 were submitted to confining pressures of 50 , 100 , and $200 \mathrm{kPa}$, whereas for slope 2 the adopted confining pressures were 50,100, 200, and $300 \mathrm{kPa}$. The air-dried samples were exposed to drying until reaching the hygroscopic water content and later submitted to triaxial tests. Soil specimens had nominal dimensions of $5 \times 10 \mathrm{~cm}$. For the saturated samples, CD tests were performed. For unsaturated specimens, suction-controlled tests were performed, employing a high air entry value porous ceramic disk of 5 BAR. Air-dried samples were consolidated and sheared, opening the drainages to the 
atmosphere (constant water content tests). The triaxial tests results were used to carry out unsaturated shear strength analysis considering the models proposed by Fredlund et al. (1978) [2] and Vanapalli et al. (1996) [1].

\subsection{Permeability Tests}

The soil permeability was determined employing constant head tests performed inside the triaxial chamber before the back-pressure phase. The average permeability coefficients were $1.61 \times 10^{-5}$ and $5.08 \times 10^{-3} \mathrm{~cm} / \mathrm{s}$ for the first and second slopes, respectively. The higher than expected values of $k$ can be partially explained by the proximity to the bedrock and the structures (intrusions) inherited by the soil, in which coarse fractions predominate.

\subsection{Survey of climatic and hydrological data}

Precipitation data were used at 10-minute intervals and were collected from National Centre for Monitoring and Alerting of Natural Disasters (CEMADEN) [18]. Data survey considered the year of 2016 for the first slope and the year of 2018 for the second slope. These years correspond to the sampling years in both slopes. The closest weather stations to the slopes were considered.

Monthly data on potential evaporation, relative humidity, and temperature were also collected on the National Institute of Meteorology (INMET) [19] platform. The data were adequately treated for inclusion in the climate and flow analysis. Figures 5 and 6 show the rainfall data.

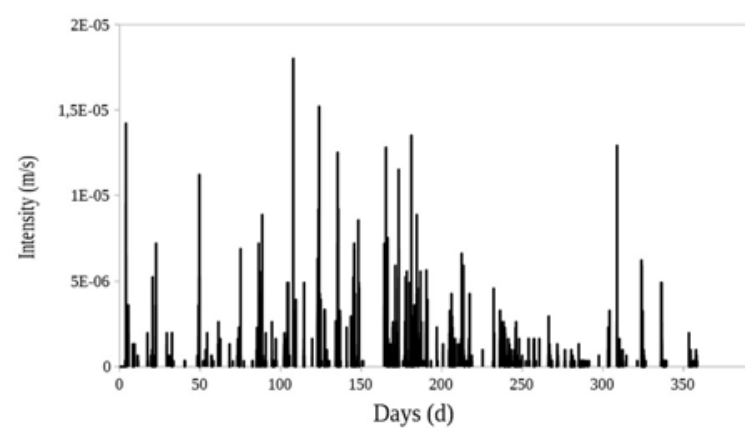

Fig. 5. Rainfall intensity along the year of 2016, slope 1.

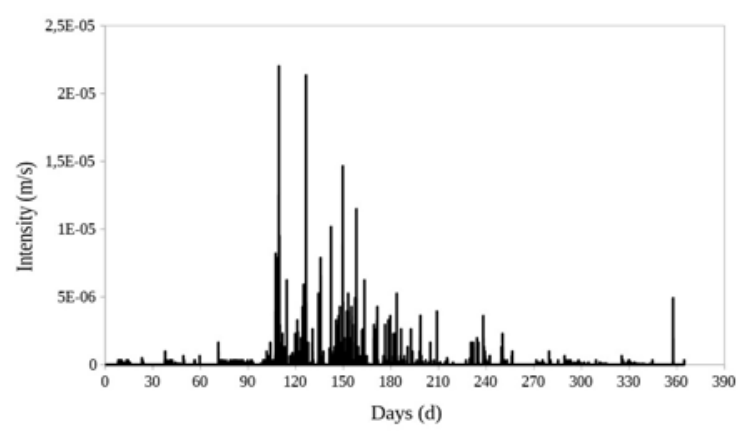

Fig. 6. Rainfall intensity along the year of 2018, slope 2 .

\subsection{Geotechnical Analysis}

The slope stability analyses were performed considering two distinct scenarios: saturated soil parameters and unsaturated conditions, evaluated in a coupled way based on rainfall intensity, evaporation rates and soil hydraulic properties using the SIGMA/W and SEEP/W software.

\subsubsection{Infiltration analysis}

In the SEEP/W, the slope geometry obtained from topographic survey and the soil parameters described previously were inserted.

The implementation of boundary conditions can be described as one of the most complex stages of the problem. The unitary flow condition equal to zero $(q=0)$ with seepage review was imposed on the slope's sides. This function is a SEEP/W "smart" boundary condition which is impervious unless there is a tendency for positive pore pressure generation. The slope base was considered as an impervious bedrock.

At the top of the slope, the soil surface boundary condition varied according to the following criteria:

- Rainfall: in this case, a unitary flow was imposed which was equal to the rain intensity.

- No rain: in this case, a negative unit flow equal to the potential evaporation was imposed.

However, as discussed above, the intensity of soil water evaporation varies according to the suction (or moisture content). Thus, two distinct functions were used to overcome this difficulty:

- Soil-climate interaction function: This function applies the concepts proposed by Wilson et al. (1997) [16], Equation 3. The data of potential evaporation $\left(E_{P}\right)$, precipitation, temperature, relative humidity, retention curve, and hydraulic conductivity of the soil are inserted. Further, the software performs a calculation of the actual evaporation over the year as a function of soil suction.

- Experimental modifying function: In this function, the ratios between the actual $(\mathrm{E})$ and potential evaporation $\left(E_{P}\right)$ measured experimentally are related to the soil suction. As verified in the evaporation tests, soil water evaporation intensity reduces as the soil dries (due to increased suction values). Thus, the modifying function was derived linking evaporation to soil suction, employing the SWRC.

Figure 7 shows the curve of the modifying function used for the condition of no rain occurrence. Figure 8 summarizes the unitary flow variation after implementing the modifying function and the rainfall intensity data throughout 2016. 


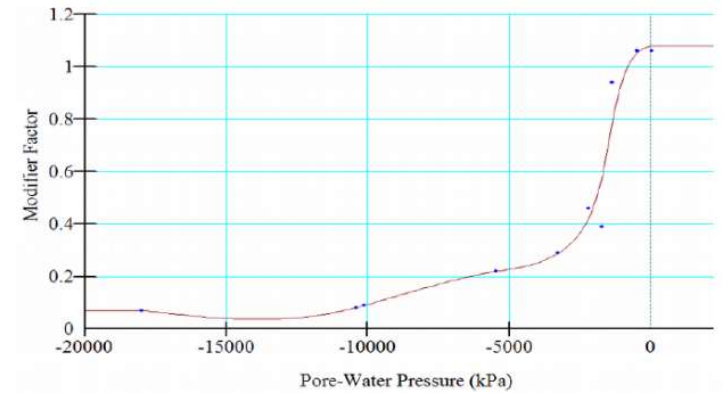

Fig. 7. SEEP/W modifying function curve (Slope 1).

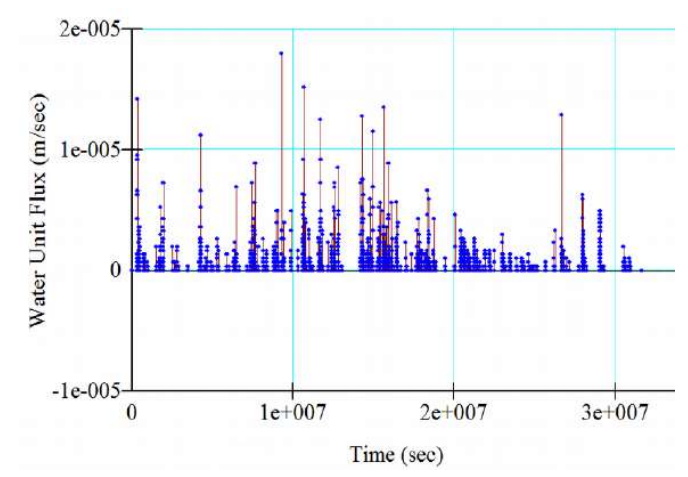

Fig. 8. Water unit flux boundary conditions applied on the slope top surface

In addition, the seepage review condition was also applied in the soil surface boundary conditions avoiding water ponding when rain intensity was higher than soil hydraulic conductivity.

Concerning the problem mesh, smaller elements were concentrated close to the soil surface, region of occurrence of the highest problem gradients, providing more accurate results and minimizing processing time penalties.

\subsubsection{Slope Stability Analysis}

The SLOPE/W and SIGMA/W software were used to verify the slope factor of safety over time. The unsaturated soil shear strength was evaluated considering the Equations 4 and 5.

Distributed loads were inserted on the top slope surface representing the buildings and had a magnitude of $10 \mathrm{kN} / \mathrm{m}^{2}$, a reasonable value for masonry buildings with up to 2 floors. The search for the critical slip surface of the slope was performed using the grid and radius option. The Morgenstern-Price method (1965) [20] was used to analyze the stability of the slopes.

\subsubsection{Summary of Geotechnical Analyses}

The geotechnical analyses conditions (saturation, soilatmosphere interactions and unsaturated shear strength models) employed in the simulations are summarized as follows:
(I) - Saturated;

(II) - Unsaturated, evaporation test, modifying function and constant $\phi^{\mathrm{b}}$ (FREDLUND et al., 1978) [2] ;

(III) - Unsaturated, evaporation test, modifying function and Vanapalli et al. (1996) [1] solution;

(IV) - Unsaturated, soil-climate interaction, and constant $\phi^{\text {b; }}$ (FREDLUND et al., 1978 [2]);

(V) - Unsaturated, soil-climate interaction, and Vanapalli et al. (1996) [1] solution.

\section{Results}

\subsection{Relationship between actual evaporation and potential evaporation}

Figures 10 shows the $E / E_{P}$ variation with soil volumetric water content for both slopes.

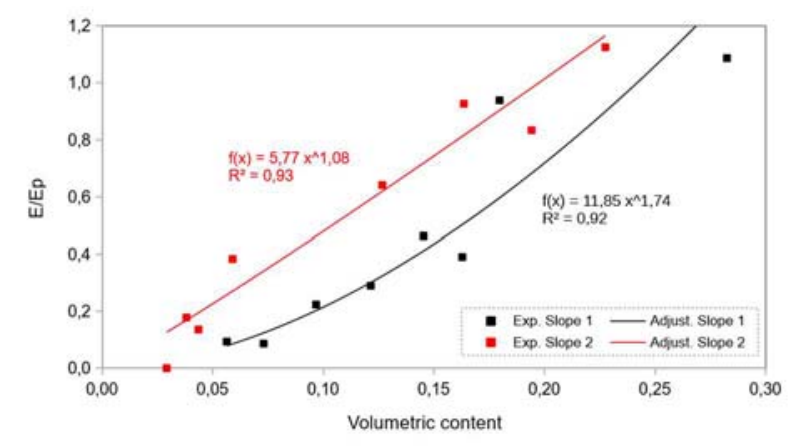

Fig. 10. Relationship between evaporation potential and actual evaporation of water in the soil for Slope 1 and 2.

As can be observed, although both curves are similar, soil from slope 1 presents lower evaporation rates than soil from slope 2, for the same water content.

\subsection{Hydraulic conductivity of soils}

Figures 11 presents the hydraulic conductivity curves estimated for the soils. As expected, the hydraulic conductivity curves present smaller variations in permeability up to the soil air entry value (see Figure 3 ). After that, due to the soil desaturation, there is a shaper decrease in the soil permeability.

Table 3 shows the obtained soil shear strength parameters for the tests performed. 


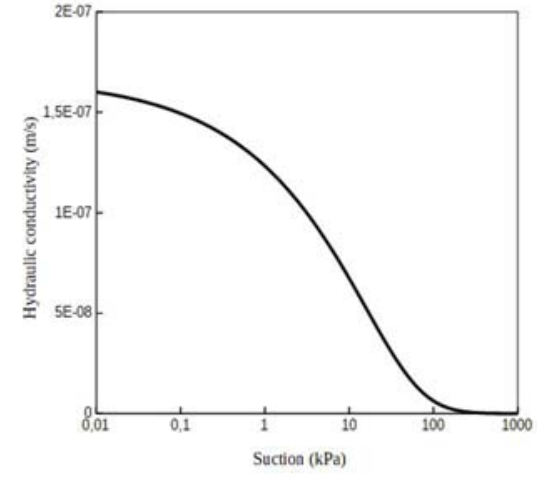

a)

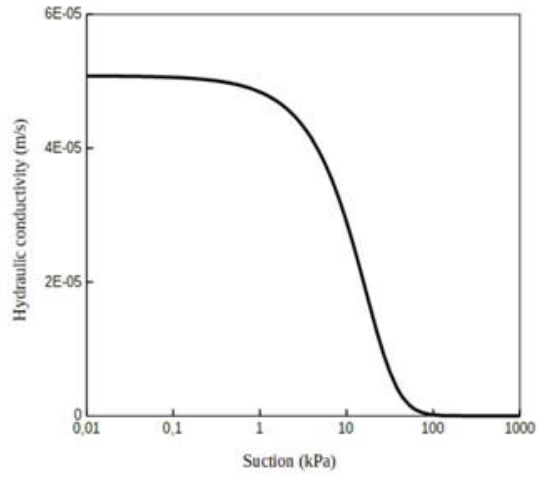

b)

Fig. 11. Hydraulic conductivity curves for a) slope 1 and b) slope 2 .

\subsection{Saturated and controlled suction triaxial tests}

Table 3. Soil shear strength parameters

\begin{tabular}{ccccc}
\hline Soil & $\boldsymbol{\theta}(\mathbf{\%})$ & $\boldsymbol{\Psi}(\mathbf{k P a})$ & $\mathbf{c}^{\prime}(\mathbf{k P a})$ & $\boldsymbol{\phi}^{\prime}\left(\mathbf{(}^{\mathbf{}}\right)$ \\
\hline \multirow{3}{*}{ Slope 1 } & 61.9 & 0 & 5.3 & 33.0 \\
& 27.8 & 483 & 59.8 & 34.4 \\
& 6.2 & 15904 & 45.2 & 33.2 \\
\hline \multirow{2}{*}{ Slope 2 } & 55.7 & 0 & 28.2 & 25.2 \\
& 28.9 & 50 & 62.6 & 26 \\
& 3.0 & 23110 & 191.5 & 19.3 \\
\hline
\end{tabular}

Soil from Slope 1 presented a peak in the shear strength as a function of suction, whereas higher shear strength parameters were obtained to air-dried conditions for Slope 2. Micro-cracks' appearance can explain the reduction in shear strength even with increased suction during the drying process.

\subsection{Slope stability analysis}

Figures 12 and 13 show the results of the slope stability analysis performed employing the soil saturated shear strength parameters. It can be noted that, although the FS values are higher than the unit and consequently indicate a tendency of non-rupture, they are less than the minimum (1.50) required by ABNT NBR-11682 (2009) [21] standard for the stability of slopes.

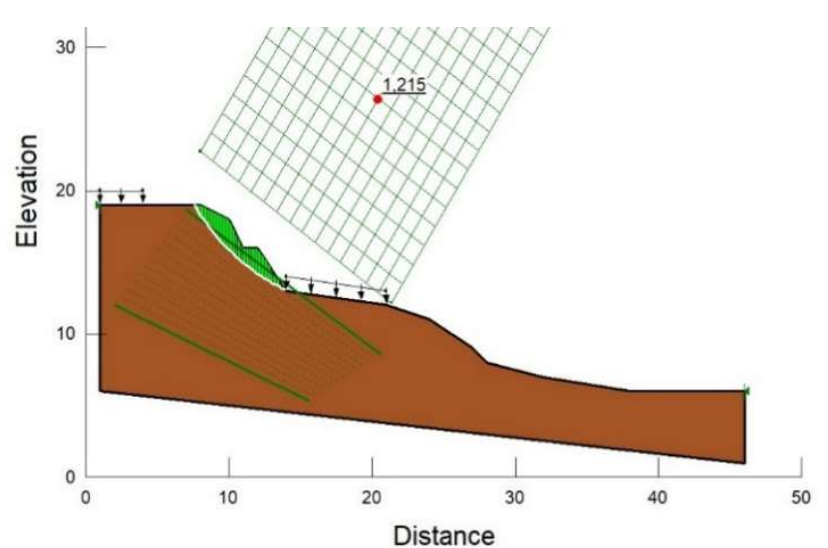

Fig. 12. Stability analysis of Slope 1 for saturated soil.

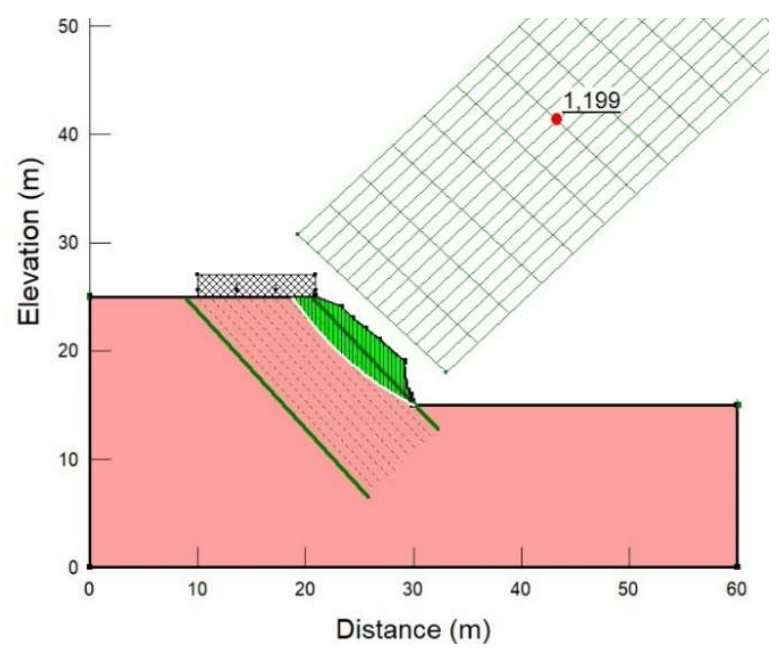

Fig. 13. Stability analysis of Slope 2 for saturated soil.

Figure 14 shows the variation of the factor of safety over the year for each analysis. 

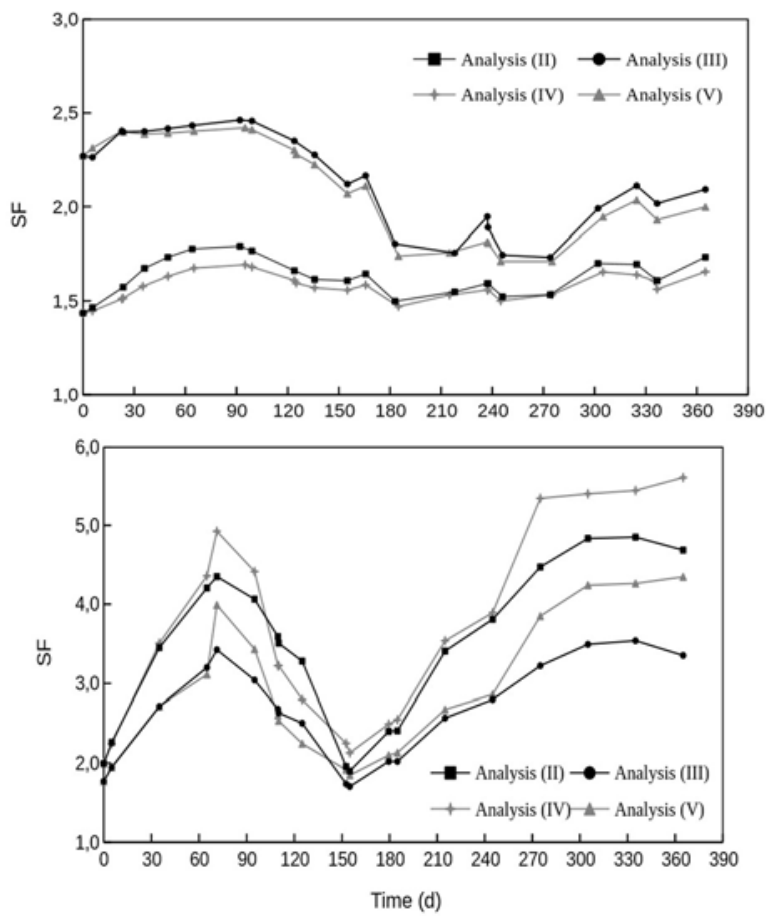

Fig. 14. Variation of the factor of safety throughout 2016 for a) slope 1 and b) slope 2 .

As can be seen, the range of variation of FS for slope 1 is within the interval [1.7;2.7]. Concerning Slope 2, the range is even wider, varying between 1.7 to 5.5 . For all the performed analysis, the higher FS values are obtained at the end of the drought period and the lower FS at the end of the rainy season, related to a higher interstitial water pressure value in the slope mass. Table 5 summarizes the minimum values of FS obtained in the performed analysis.

Table 5. Minimum FS values for the performed analysis

\begin{tabular}{l|c|c|c|c|c}
\hline Analysis & I & II & III & IV & V \\
\hline Slope 1 & 1.215 & 1.390 & 1.731 & 1.470 & 1.918 \\
Slope 2 & 1.199 & 1.900 & 1.699 & 2.130 & 1.846 \\
\hline
\end{tabular}

Considering the data presented in Table 5 and Figure 14 and comparing the results of the different performed analysis, it is observed that:

Both slopes showed more conservative FS values when applying the modifying function (analysis II and III). This illustrates the importance of performing evaporation tests in order to more properly access soil/atmosphere interactions. However, the choice of the unsaturated shear strength model had a more important role in the obtained values of FS than the soil-atmosphere interactions model.

For Slope 1 (Figure 15), minimum FS values were obtained using the Fredlund et al. (1978) [2] model whereas for Slope 2, both methods tend to present similar values in the raining period. On the other hand, there are significant differences in the FS values obtained for the drought periods, reflecting the differences in the unsaturated cohesion of the soils for suction values greater than $100 \mathrm{kPa}$ (use of models that consider $\phi^{\mathrm{b}}$ constant or variable and the influence of the range of suction employed in the $\phi^{\mathrm{b}}$ determination).

It can also be observed that none of the slopes reached the FS values obtained considering the soil as entirely saturated.

\section{Conclusion}

This paper analyses the influence of soil-atmosphere interactions and shear strength models on slope stability. It was possible to verify that currently, there are tools that allows modelling the slope behaviour over time, considering the soil unsaturated properties and climate data provided by weathering stations. In the performed simulations, even in the most severe raining periods analysed, none of the analysed slopes achieved total soil saturation, indicating the importance of considering unsaturated soil parameters to provide more economic and safe design premises.

However, it was seen that the choice of the unsaturated shear strength model influences heavily the obtained FS values. In the case of the Fredlund et al. (1978) shear strength equation, the use of higher suction secant values of $\phi^{\mathrm{b}}$ can avoid overestimates in the computed FS values. This was the case of the slope 1 , where the $\phi^{\mathrm{b}}$ value was calculated considering a suction of $500 \mathrm{kPa}$.

Furthermore, it is essential to consider the conditions surrounding the slope since there may be other sources of soil saturation, such as leaking pipes or the absence of drainage devices in the slope.

\section{Acknowledgments}

The authors wish to thank the Environmental Geotechnical Laboratory of the Polytechnic School of UFBA (GEOAMB-UFBA) for the infrastructure to carry out this work.

\section{References}

1. S. K. Vanapalli, D. G. Fredlund, D. E. Pufahl, and A.W. Clifton (1996). Model for the Prediction of Shear Strength with respect to Soil Suction. Canadian Geotechnical Journal, Vol. 33, p. 379-392.

2. D. G. Fredlund, et al. (1978). The shear strength of unsaturated soils, Canadian Geotechnical Journal, 15: 3, p. 313-321.

3. O. M. Vilar (2007). An expedite method to predict the shear strength of unsaturated soils, Soils and Rocks. 30, p. 51-61.

4. P. S. Sousa (2006). Comportamento mecânico e hidráulico de um solo residual do granulito-gnaisse de Salvador e sua aplicação no estudo de mecanismos de 
instabilização de taludes. Dissertation - Federal University of Bahia, Polytechnic School, Salvador.

5. GEOSLOPE International Ltd. (2018). Stability Modelling with GeoStudio. Calgary, Alberta, Canadá.

6. K. Terzaghi (1925). Erdbaumechanick, Viena, Franz Deutcke, Áustria.

7. K. Terzaghi, O. K. Frohlich. (1936). Theorie der setzung von tonschichten, Franz Deuticke. Vienna, Áustria.

8. H. Darcy. (1856) Les fontaines publiques de la ville de Dijon. Victor Dalmont, Paris.

9. P.G. Nutting (1930). Physical analysis of oil sands. Am. Assoc. Petroleum Geologists Bull. v. 14, p. 13371349 .

10. V. Escário, J. Saez (1986). The shear strength of partly saturated soils, Géotechnique, vol. 36: 3, p. 453456.

11. V. Escário, J. F. T. Jucá (1989). Strength and deformation of partly saturated soils. In: Proceedings of the $12^{\text {th }}$ international conference on soil mechanics and foundation engineering (ICSMFE), Anais, Rio de Janeiro, vol. 1, p. 43-46.

12. D. G. Fredlund, A. Xing (1994). Equations for the Soil-Water Characteristic Curve. Canadian Geotechnical Journal. 31 (3), p. 521-532.

13. M. Th. van Genutchen, (1980). A closed-from equation for predicting the hydraulic conductivity of unsaturated soils, Soil Science Society of America Journal, Vol. 44, p. 892-898.

14. G. P. D. Vivacqua (2012). Estudo da influência da interação solo-atmosfera nos perfis de umidade, sucção e temperatura de um subsolo não saturado. Dissertation Technology Center of the Federal University of Espírito Santo, Vitória, Brazil.

15. M. S. C. São Mateus, S. L. Machado, M. C. Barbosa (2011). Estudo da evaporação em camada de cobertura de aterro de RSU - comparação entre medições de campo e resultados obtidos com a aplicação das equações de Wilson (1990) e Wilson et al. (1997). VII Brazilian Symposium on Unsaturated Soils, 1, p. 283-290.

16. G. W. Wilson, D. G. Fredlund, Barbour, S. L. (1997): The Effect of Soil Suction on Evaporative Fluxes from Soil Surfaces. Can. Geotech. J. 34 p. 145-155.

17. A. W. Bishop (1959). The principle of effective stress, Tecknish Ukeblad, Vol. 106, p. 859-863.

18. National Center for Monitoring and Natural Disaster Alerts (CEMADEN). Available at: <http://www.ce maden.gov.br/>. Accessed on: jan. 2020.

19. National Institute of Meteorology (INMET). Available at: <https://bdmep.inmet.gov.br/> Accessed on: jan. 2020.

20. Morgenstern, N.R. e Price, V.E. (1965). The Analysis of the Stability of General Slip Surfaces, Géotechnique, Vol. 15, p. 79-93.

21. NBR-11682 (2009). Estabilidade de encostas. Brazilian Association of Technical Standards (ABNT), Rio de Janeiro, Brazil. 